\title{
Reviews
}

Strabismus 0927-3972/96/US\$10.50

Strabismus-1996, Vol. 4, No. I,

pp. 25-40

(C) Aolus Press

Buren (The Netherlands) 1996

Accepted 20 February 1996

\section{Robinson's computerized strabismus model comes of age}

\author{
H. J.Simonsz \\ H.Spekreijse
}

\author{
Department of Ophthalmology, University Hospital Dijkzigt, \\ NL 3015 GD Rotterdam and the Netherlands Ophthalmic Research \\ Institute, Amsterdam, The Netherlands
}

\begin{abstract}
In this article we review our further development of D.A. Robinson's computerized strabismus model. First, an extensive literature study has been carried out to get more accurate data on the anatomy of the average eye and the eye muscles, and about how these vary with age and with refraction. Secondly, the forcelength relations that represent the mechanical characteristics of the eye muscles in the model have been determined more accurately in vivo recently, and the model was changed accordingly. Thirdly, many parameters that were free in the original model and not derived from in vivo measurements were replaced by derivatives from in vivo measurements or made redundant. Fourthly, the ease of operation was improved greatly and the algorithms were made so much faster that a calculation for nine positions of gaze now takes ten seconds on a handheld HP 200LX Palmtop. The predictions of the model compared well with clinical results in horizontal muscle surgery, oblique muscle surgery, forced duction tests and abducens, oculomotor or trochlear palsies. Consequently, complex strabismus surgery in our clinic is now guided by the predictions of the computerized model.
\end{abstract}

Key words Eye movement; strabismus; biomechanics

Introduction In 1975, Robinson presented a computerized model describing the static mechanical proper- ties of the eye and its muscles. Contrary to the expectations of many, the model has not yet found general application. The reason for this is that there are several conditions to be met before a computerized strabismus model can be used by an ophthalmologist or an orthoptist. The anatomy and physiology of eye and eye muscles should be described accurately. The model should predict the effects of surgery, a palsy or another event with reasonable accuracy. Handling should be clear and simple. These and other conditions were not fully met when Robinson originally presented the model, which has retarded its introduction.

Early attempts to use the computerized model clinically were made by France and Durbanks (1978, 1979). Haase and Kusel, in their version of the model, addressed the problem that the eye muscles in Robinson's model were modelled as strings (Haase, I977; Haase and Kusel, 1977; Kusel and Haase, 1977), whereas eye muscles are really shaped like bands (Ruete, I 857). They revived the concept of Helmholtz (1910) that, in eye movements out of the plane of the muscle, only one side of the band-like tendon is taut, whereas the other side is slack.

Later work on the computerized model was done by Richard Clement. One of his interesting observations was that, in the computerized model, a superior oblique palsy caused far less hypertropia than is seen clinically in most patients that are diagnosed as having superior

This study has been published, in part, as a thesis by the first author (Simonsz, I990).

Address for correspondence: H.J. Simonsz, Molewaterplein 40, NL 3015 GD Rotterdam, The Netherlands.

Phone: 3I.I0.4639222 beeper 3394 
oblique palsies (Clement, 1982). In other studies by Clement and Howrie (1985) and by Boylan and Clement (1987). V-and A-motility patterns and several tests of ocular motility were analyzed.

Kault et al. (1987) studied the influence of the size of the eye. sideslip of eye muscles and the relation between force and length. Kault et al. (1989) also presented a method for automatic parameter searching employing a computerized learning paradigm using a database with results of the model in a summarized form.

Miller (1984) has made the model binocular, translations of the eye (i.e. displacements of the center of the eye) were accounted for and sideslip of an eye muscle over the surface of the eye. in eye movements out of the plane of the muscle. was restricted. He quantified these effects and studied the effect of modelling the muscles as bands instead of strings.

Later he examined sideways displacement of eye muscles in eye movements out of the plane of the muscle (like horizontal rectus muscles in upgaze. for instance) with X-rays of radio-opaque markers implanted in monkey eye muscles (Miller and Robins. 1987) and with MRI in humans (Miller. 1989).

Miller has made his version of the computerized model commercially available. made it menu driven and very user friendly. He added magnificent graphics displaying the anatomy of the eye and eye muscles in various positions of gaze. The action of muscle pulleys that keep the eye muscles in place in the orbit, in eye movements out of the plane of the muscle (Demer et al. 1995), was recently added to Miller's model.

There are fundamental differences between the approaches of Clement. Miller and ours. Miller's approach

Fig. I. As in Robinson's original model, the path of the muscle is represented in the computerized model by a string. so to speak. from origin to insertion. The shortest path over a globe is always the are of a great circle (upper trace). Robinson already knew that the muscles did not follow the shortest path over the eye in eye movements out of the plane of the muscle like Krewson had assumed. because that caused too much bridle effect and too much twist of the muscle at the insertion. He instead described the path of the muscle over the globe as the arc of a lesser circle on the globe (middle trace). defined by restricting the permitted twist at the insertion. In our model, no twist of the muscle at the insertion is permitted (lower trace) to leave the belly of the muscle as much as possible in the same place, when the eye moves out of the plane of the muscle. The vertical circle depicts the locus of tangents from the origin to the globe, the three dots represent the theoretical points of tangency for the three muscle paths. is characterized by the accuracy of the anatomy of the model, excellent programming, a user-friendly interface and superb graphics. In Clement's approach, the accuracy of the clinical predictions of the model are emphasized. We have concentrated on gaining better control over the model ( 1 ) by doing additional studies to clarify unknown parameters and (2) by making the model as straightforward as possible. These different lines of development complicate direct comparisons between the children of the parent model.

This article provides an overview of our further development of the computerized strabismus model over the past ten years.

ROBINSON'S ORIGINAL MODEL The computerized eye position model that Robinson developed in 1975 consisted of two programs. The first program derived the levels of innervation of the six eye muscles from a given eye position, whereas the second program derived the eye position from the levels of innervation of the six eye muscles. The level of innervation of two muscles of a pair were reciprocal, so that only three pairs of innervation had to be calculated. The eye was represented as a sphere that could freely rotate about its center, being only restricted in rotation by elastic connective tissue that turned the eye back to gaze ahead and by the six eye muscles. The mechanical characteristics of the eye muscles were represented by a given relation between force, length and innervation. Muscle force of each muscle was scaled according to relative cross-sectional area and, reciprocally, to muscle length.

The path of the muscle was represented by a string, so to speak, from origin to insertion. Robinson already knew that the muscles do not follow the shortest path over the eye in eye movements out of the plane of the muscle as Krewson (1950) had assumed, because that causes too much bridle effect and too much twist of the muscle at the insertion. The shortest path over a globe is always the arc of a great circle (Fig. I, upper trace). From this the direction of pull of the muscles could be

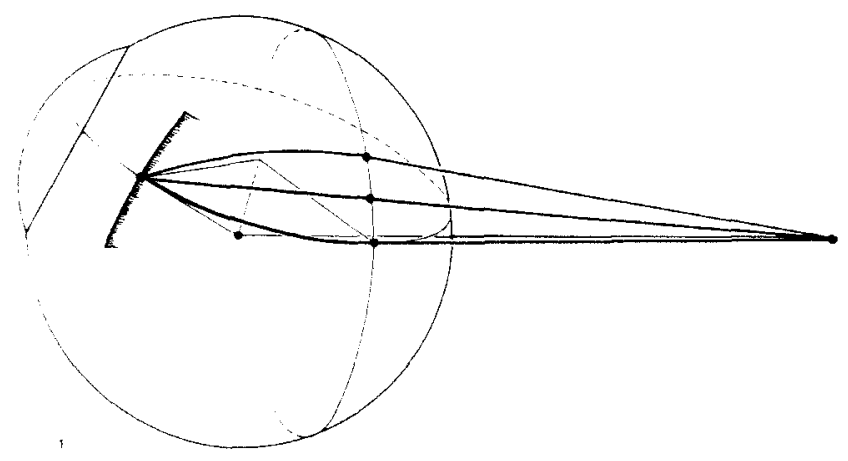


calculated. Robinson assumed, however, that an eye muscle pulled on the eye at the point of tangency.

Both programs used a set of parameters describing the anatomy of an average adult eye (eye size, insertions and origins). These were based on a study by Volkmann on 30 skulls ( I869), quoted by Krewson (I950).

Methods \& Results In the following I will describe the modifications that we have applied to the model over the past years in detail. The description of the anatomy of the model eye, the muscles and the orbit was improved by an extensive literature search. The description of the mechanical characteristics of the model eye was improved with data obtained recently. Finally, the direction of pull of the eye muscles has been the subject of many recent studies and these results were also implemented in the model.

SIZE OF EYE AND ORBIT The size of the eye varies primarily with age, sex and refraction. In the model, the radius of the eye, equal to half of its transverse diameter is used for the size of the eye. Clinicians use axial length, however, to indicate the size of the eye, as this value can be easily measured in a patient with ultrasonography. Therefore, axial length is entered as input parameter and from that the transverse diameter of the eye is derived. Alternatively, age, sex and refraction of the patient can be entered to estimate the axial length and radius of the eye using approximations described below.

From axial length a scaling factor is derived that is multiplied with (I) the radius of the eye, (2) the locations of origins and insertions (representing the size of the orbit), (3) the spring constants of the muscles, (4) the force of a horizontal rectus muscle in primary position, used as an input parameter to calculate the force-length relation for a contracting muscle, (5) the exponential force-length relation for a non-contracting muscle and (6) the spring constant in deformation of the connective tissue surrounding the eye in passive eye rotation. These parameters will be discussed later.

For the adult eye in the model, the data of Lang et al. ( 1980 ) were used. The diameter of the average adult eye was set at $23.4 \mathrm{I} 25 \mathrm{~mm}$, equivalent to an axial length of $24.325 \mathrm{~mm}$. Lang et al. (I980) found $24.325 \mathrm{~mm}$ for axial length, $23.23 \mathrm{~mm}$ for vertical diameter and 23.595 $\mathrm{mm}$ for transverse diameter of the eye, on average, in a large series of measurements. (Please note that the use of $0.01 \mathrm{~mm}$ precision in some of the data to follow does not reflect the precision of the original data.)

Larsen ( I97I) measured axial length in a large series of children with ultrasonography. He found three growth phases to occur till puberty. These were described in the model with the following 3 equations:

For the age group between 4 and I 6 years of age:

Ultrasonic axial length $(\mathrm{mm})=20.8+0.17 \mathrm{I} \times$ age,

Between $\mathrm{I} .7$ and 4 years of age:

Ultrasonic axial length $(\mathrm{mm})=20.0+0.375 \times$ age,

Under $\mathrm{I} .7$ years of age:

Ultrasonic axial length $(\mathrm{mm})=\mathrm{I} 7.2+2.068 \times$ age,

To the ultrasonic axial length the thickness of the posterior sclera, chorioid and retina, about I $\mathrm{mm}$, is added. Eyes of female patients were $0.4 \mathrm{~mm}$ shorter than those of male patients, on average, and this is also taken into account. Tatsugami et al. (1980) found approximately I $\mathrm{mm}$ axial length difference per 3 diopters of refractive error. The latter two are taken into account when deriving axial length from age, sex and refraction.

As an example, in a 4-year-old girl with a $+4 \mathrm{D}$ hypermetropia, the effect of a $5 \mathrm{~mm}$ recession would be I $6 \%$ larger than its effect in an emmetropic adult.

Weiss ( 1890 ) found approximately the same values as Larsen. Tatsugami et al. found the eyes of Japanese children to be approximately I $\mathrm{mm}$ longer than those studied by Larsen. Merkel and Orr (I 892) found $17.5 \mathrm{~mm}$ for axial length in newborn.

ORIGINS AND INSERTIONS The locations of the origins and the insertions of the muscles are expressed in millimeter coordinates $\mathrm{x}, \mathrm{y}, \mathrm{z}$, with the center of the eye being point $0,0,0$. The $\mathrm{x}$-axis is transverse, temporal being positive; the $y$-axis is sagittal, anterior being positive; the $z$-axis is vertical, up being positive. These are Fick's axes ( 1854 ), the sign of the y-axis having been reversed by Krewson (1950). In the model, Robinson (1975) had used the muscle origin and insertion coordinates as quoted by Krewson (I 950), who had taken these data from a study by Volkmann on 30 skulls ( I 869), improving on earlier measurements by Fick (I854) and Ruete (I 857).

Unfortunately Krewson misquoted Volkmann. He said that the coordinates had been corrected, as suggested by von Helmholtz, to let the center of the eye and the center of rotation coincide. Neither were they corrected for this reason, nor had von Helmholtz suggested it. Volkmann wanted to use the center of rotation as reference point for the coordinate system, not the center of the eye, and he had assumed that the point of rotation was $1.29 \mathrm{~mm}$ behind the center of the eye. Donders and Doijer ( 1862 ) had found, in 15 emmetropes, that the center of rotation was $10.94 \mathrm{~mm}$ behind the base of the cornea (II.96 mm for myopes and I0.64 mm for 
hypermetropes), or $13.54 \mathrm{~mm}$ behind the apex of the cornea. Confirming the work of Doijer, Volkmann himself found the center of rotation in Io emmetropes to be II.I $8 \mathrm{~mm}$ behind the center of the pupil. To determine the distance between the center of the eye and the center of rotation he subtracted the radius of the eye: $\mathrm{I} 2.25 \mathrm{~mm}$ (derived by him from measurements on Io post-mortem eyes) from the $13.54 \mathrm{~mm}$ found by Doijer and Donders, the result being $1.29 \mathrm{~mm}$.

Hence, to get the coordinates of origins and insertions with the center of the eye as reference point, $1.29 \mathrm{~mm}$ should be added to Volkmann's or subtracted from Krewson's y-coordinates. After this correction the discrepancies noted earlier (R.A. Clement, personal communication), between the distances between the various insertions and the point $(0,0.0)$ vanish.

The description of Volkmann's determination of the location of the center of the eye in the orbit, and of the location of the origins is detailed and impressive. The number of skulls he examined, 30 , also seems sufficient. There is a print error in his work. namely that the $y$ coordinate of the medial rectus is $3.0 \mathrm{~mm}$, whereas that of the lateral rectus is $34 \mathrm{~mm}$ and that of the vertical rectus muscles is $31.76 \mathrm{~mm}$; Krewson "s assumption that the true value was $30 \mathrm{~mm}$. was probably incorrect: Volkmann found the foramen opticum to be $31.76 \mathrm{~mm}$ posterior to the frontal plane through the center of rotation and only noted that the origin of the lateral rectus was further behind this plane. $34 \mathrm{~mm}$. because it originated from the lesser sphenoid wing. Hence, in our model the origin of the medial rectus muscle is also assumed to be at $31.76 \mathrm{~mm}$.

Volkmann's measurements of the insertions of the rectus muscles, however, were derived indirectly. by applying the distances between these insertions and the corneal limbus. as measured by other authors. to his 12.25 -mm-radius eye. This is a very unreliable procedure, especially as the distances between insertions and limbus were not correct. He derived the location of the insertion of the oblique muscles indirectly from the location of their origins and the angle of the oblique muscle with the sagittal plane.

Hence for the location of the insertions of the rectus muscles the measurements of Lang et al. (1980) on 59 eyes seem preferable. The average diameter of these eyes was transversely: $23.63 \mathrm{~mm}$ for the right and 23.56 $\mathrm{mm}$ for the left eye: vertically: $23.28 \mathrm{~mm}$ for the right and $23.18 \mathrm{~mm}$ for the left eye. The average diameter of the corneae was transversely: I I.70 $\mathrm{mm}$ for the right, and $12.08 \mathrm{~mm}$ for the left eye, and vertically: $10.80 \mathrm{~mm}$ for the right and $11.06 \mathrm{~mm}$ for the left eye (differences at least partly resulting from chance). The distances between the middle of the insertions of the lateral, medial, superior and inferior rectus muscles and the limbus were: $7.5 \mathrm{~mm} .5 .8 \mathrm{~mm}, 7.65 \mathrm{~mm}$ and $6.7 \mathrm{~mm}$, respectively. Some calculation work then yields for the $\mathrm{x}, \mathrm{y}, \mathrm{z}$ coordinates of the insertion of the lateral rectus muscle: I $0.89,4.55$, o mm, for those of the medial rectus muscle:- $10.08,6.13,0 \mathrm{~mm}$, for those of the superior rectus muscle: $0,4.63,10.65 \mathrm{~mm}$, and for those of the inferior rectus muscle: $0,5.53,10.22 \mathrm{~mm}$.

The insertions of the vertical rectus muscles are located, however, slightly temporally of the mid-sagittal plane of the eye, approximately $0.75 \mathrm{~mm}$ (derived from Lang et al., I 980, his Fig. 5) and can be located at: 0.75, $4.62,10.63 \mathrm{~mm}$ for the superior and: $0.75,5.5 \mathrm{I},-\mathrm{I} 0.20$ $\mathrm{mm}$ for the inferior rectus muscle. The latter is important as placement exactly in the mid-sagittal plane would cause a slight bridle effect of the vertical rectus muscles even in primary position.

The $y$-coordinates of the insertions of the superior and inferior oblique muscles can be derived from (I) the distances between the insertions of the oblique muscles and the limbus, (2) the average horizontal and vertical diameter of the eye and (3) the average horizontal and vertical diameter of the cornea (all data from Lang et al., 1980 ), resulting in $-6.50 \mathrm{~mm}$ for the superior and -9.12 $\mathrm{mm}$ for inferior oblique muscle (Volkmann found 5.70 and $8.47 \mathrm{~mm}$ ).

Fink ( 1962 , his Fig. 3) found that the middle of the insertion of the superior oblique muscle is approximately as much temporal from the mid-sagittal plane as the middle of the superior rectus insertion. However, Volkmann found it to be $2.9 \mathrm{~mm}$ temporally of the midsagittal plane of the eye. From surgical experience, we would suggest that the truth is probably in between the two: $2 \mathrm{~mm}$ seems a reasonable guess for this highly variable insertion. The z-coordinate is determined by and derived from the $\mathrm{x}$ - and the $\mathrm{y}$-coordinate. Accordingly, the coordinates of the insertion of the superior oblique muscle are set at: $2.00,-6.50,9.53$

The anterior edge of the insertion of the inferior oblique muscle was, on average, $2.09 \mathrm{~mm}$ more cranial than the lower edge of the insertion of the lateral rectus muscle in Fink's measurements ( 1962). As the insertion of the lateral rectus muscle was $10.78 \mathrm{~mm}$ wide in his measurements, the anterior edge of the insertion of the inferior oblique muscle was $3.3 \mathrm{~mm}$ below the horizontal plane through the center of the eye. The angle between the insertion line of the inferior oblique muscle and the horizontal plane was $15-20^{\circ}$, its length was $9.5^{8}$ $\mathrm{mm}$ (Fink, 1962), whereas its posterior edge was I mm 
below the macula. Hence the middle of the insertion was approximately $2 \mathrm{~mm}$ below the horizontal meridian. The $\mathrm{x}$-coordinate is derived from the $\mathrm{y}$ - and the $\mathrm{z}$-coordinate. Accordingly, the coordinates of the inferior oblique insertion would then be: $7.06,-9.12,2.00$.

Based on these coordinates for insertions and on Volkmann's coordinates for origins of the muscles, the angles between the superior and inferior rectus muscles and the sagittal plane are $23.97^{\circ}$ and $23.48^{\circ}$, which is realistic. The angles between the superior and inferior oblique muscles and the sagittal plane are $52.09^{\circ}$ and $42.09^{\circ}$, which is unrealistic, because the average angles for superior and inferior oblique muscles are approximately the same and closer to $52^{\circ}$ than to $42^{\circ}$ (Fink, 1962). We therefore, rather arbitrarily, reduced the ycoordinate of the inferior oblique muscle origin towards that of the superior oblique muscle: 6.95 instead of I $1.05 \mathrm{~mm}$. The angle then becomes $47.95^{\circ}$. The origin and insertion coordinates used in our model are summarized in Table. I.

EYE MUSCLE LENGTH Robinson (1975), following Krewson's citation (I950) of Volkmann (I869), assumed that the lengths of the muscles were widely different (LR: 49.I I, MR: 38.5I, SR: 4I.96, IR: 42.49, SO: 22.28, 1O: $35.35 \mathrm{~mm}$ ). This concerned muscle with tendon, however (apart from SO). Actually, Volkmann had also measured the length of the muscular part of each muscle alone and had found that, for all four rectus muscles, the muscular parts were approximately equal in length.

In the relation between force and length of the eye muscles in Robinson's model, changes in muscle-length were expressed in percent length-change. Consequently, longer muscles had lower spring constants. This especially distorted the ratio between the spring constants of medial and lateral rectus. In accordance with the finding of Volkmann that the muscular parts of the four rectus muscles are equal in length and in accordance with our in vivo finding (Simonsz et al., 1988; Simonsz, I 994), that antagonist muscles have approximately equal spring constants, in our model the spring constants are set equal for each muscle of a pair of antagonists.

As in Robinson's original model, the path of the muscle is represented by a string, so to speak, from origin to insertion. However, the muscles do not follow the shortest path over the eye in eye movements out of the plane of the muscle (the shortest path over a globe is always the arc of a great circle, Fig. I, upper trace). Robinson had described the path of the muscle over the globe as the arc of a lesser circle on the globe, by restricting the permitted twist of the muscle tendon at the insertion (Fig. I, middle trace). In our model, to leave the belly of the muscle as much as possible in the same place when the eye moves out of the plane of the muscle, no twist of the muscle at the insertion is permitted (Fig. I, lower trace). The muscle leaves the insertion always in the same direction perpendicular to the insertion line, then to follow a path over the globe that is an arc of a lesser circle on the globe, towards the theoretical point of tangency. The length of the arc of contact is calculated and subtracted from the arc of contact of the muscle with the eye in primary position to obtain the change in muscle length. Note that the distance from the origin to the point of tangency is always the same.

Although the path of the muscle in vivo is slightly

Table I. Location of origins and insertions in Robinson's original model (top) and in our model (below). Expressed in millimeters, Fick's coordinates: x: horizontal, y: sagittal, z: vertical. The center of the eye is point $0,0,0$.

\begin{tabular}{|c|c|c|c|c|c|c|c|}
\hline & & LAT & MED & SUP & INF & SUP OBL & INF OBL \\
\hline \multirow[t]{3}{*}{ Insertions: } & $\mathrm{x}$ & I 0.0800 & -9.6500 & 0.0000 & 0.0000 & 2.9000 & 8.7000 \\
\hline & $\mathrm{y}$ & 6.5000 & 8.8400 & 7.6300 & 8.0200 & -4.4100 & -7.1800 \\
\hline & $\mathrm{z}$ & .0000 & .0000 & I 0.4800 & -10.2400 & I I.0500 & 0.0000 \\
\hline \multirow[t]{3}{*}{ Origins: } & $\mathrm{x}$ & -13.0000 & -17.0000 & -I 6.0000 & -I 6.0000 & -15.2700 & -I I. 1000 \\
\hline & $\mathrm{y}$ & -34.0000 & -30.0000 & -31.7600 & -31.7600 & 8.2400 & I I. 3400 \\
\hline & $\mathrm{z}$ & .6000 & .6000 & 3.6000 & -2.4000 & I 2.2500 & -15.4600 \\
\hline \multirow[t]{3}{*}{ Insertions: } & $\mathrm{x}$ & І 0.8858 & -10.0826 & 0.7500 & 0.7500 & 2.0000 & 6.7173 \\
\hline & y & 4.5475 & 6.1256 & $4.6 \mathrm{I} 74$ & 5.5139 & -6.4972 & -9.1197 \\
\hline & $\mathrm{z}$ & $.000 \mathrm{I}$ & $.000 \mathrm{I}$ & $10.63 \mathrm{I} 3$ & -IO.I954 & 9.4178 & -2.0000 \\
\hline \multirow[t]{3}{*}{ Origins: } & $\mathrm{x}$ & -13.0000 & -17.0000 & $-\mathrm{I} 6.0000$ & -16.0000 & -15.2700 & - I I. I000 \\
\hline & $\mathrm{y}$ & -35.2900 & -33.0500 & -33.0500 & -33.0500 & 6.9500 & 6.9500 \\
\hline & $\mathrm{z}$ & .6000 & .6000 & 3.6000 & -2.4000 & I 2.2500 & - I 5.4600 \\
\hline
\end{tabular}


different from the string model described above, we consider it acceptable. especially as it is only used to calculate muscle-length change. It is no longer used to calculate the direction of pull of the muscle (see below). When loss of tangency occurs. especially for the medial rectus muscle in far adduction and after Faden surgery, the insertion itself is taken instead of the point of tangency, and the torque imparted by the muscle to the eye is reduced accordingly.

SIDESLIP OF THE INFERIOR OBLIQUE MUSCLE VOlkmann assumed that the insertion of the inferior oblique muscle was at the same vertical level as the center of the eye. This caused the inferior oblique muscle to have an extremely large are of contact over the eye. This large arc of contact, together with the fact that Volkmann chose a very posterior insertion. caused the muscle to sideslip (the belly of the muscle slipping backwards over the eve) even in gaze ahead. The inferior oblique muscle became an abductor in abduction. Studies of the effect of isolated inferior-oblique-muscle surgery on the horizontal angle of strabismus show. however, that the change of the horizontal angle of strabismus by obliquemuscle surgery is small and can be both divergent or convergent (Stager and Parks, 1973: Diamond and Parks, 1981; Bredner-Hirr, 1976).

In vivo. sideslip is reduced by Lockwood's ligament: a connective-tissue connection between the belly of the inferior oblique muscle and the inferior rectus muscle. Günther et al. (I986; also Günther, 1986) tackled the problem of excess sideslip of the inferior oblique muscle by including Lockwood's ligament in the model as a spring connection between inferior oblique and inferior rectus. a very realistic solution. In the model of Günther

Fig. 2. Force-length-innervation relation as employed in the model. The abscissa represents length change of the muscle $(\mathrm{mm})$. the ordinate represents the level of innervation of the muscle and the vertical axis represents the force of the muscle (g). The level of innervation is expressed in units as used in the computerized model (see Methods \& Results section). Note that at low innervation (muscle not actively contracting). the force is zero at gaze-ahead length. to rise exponentially when the muscle is stretched. When the level of innervation is high (muscle strongly contracting), the force-length relation is linear. Under static conditions. when the eye is not moving. only one single value of each force-length relation is used. These points are indicated (this example concerns a lateral rectus muscle) by an asterisk for $40^{\circ}$ of abduction (left-most asterisk) $30^{\circ} \cdot 20^{\circ}, 10^{\circ}$. gaze ahead and for $10^{\circ}$. $20^{\circ}, 30^{\circ}$ and $40^{\circ}$ of adduction (right-most asterisk).
(1986). the need for Lockwood's ligament was somewhat more pronounced than in our model, for the insertion of the oblique muscle was chosen very posteriorly, near the macula $(6.73,-10.45,0.0)$. As the insertion of the inferior oblique muscle in our model is more anterior than in Günther's model, and $2 \mathrm{~mm}$ below the horizontal plane (Fink, 1962), sideslip hardly occurs in gaze ahead. Moreover, we no longer use the point of tangency to determine the direction of pull of the muscle, for other reasons (see below). The shifts of the point of tangency therefore only affect the calculated length change of the muscle in our model.

FORCE-LENGTH RELATION OF NON-CONTRACTING EYE MUSCLES The force-length relation for non-contracting skeletal muscles (the passive component) is exponential (Fung, I967; Pinto and Fung, 1973), and we found this to be valid for eye muscles also. We registered force and length of non-contracting eye muscles in 22 patients (2 I medial rectus muscles, 22 lateral rectus muscles) who had first surgery for uncomplicated horizontal strabismus (Simonsz et al., 1986, 1988). After averaging, we found the following exponential function to describe the relation appropriately:

$$
\text { force }(g)=\mu\left(e^{a \cdot m i l l i m e t e r s ~ l e n g t h-c h a n g e ~}-I\right)
$$

Where $\mu=$ I.OI04 and $\alpha=0.34024$. This relation is illustrated in Fig. 2 (rightmost, exponential curve).

At lengths shorter than the primary-position length the muscle is slack and the force is assumed to be zero. This seems a reasonable assumption: Asmussen ( 1978 ) found in rabbits that the force in a non-contracting eye muscle starts to rise from primary-position length onwards. In his experiments in rabbits, the lateral orbital wall was taken out and the length of the muscle was measured in situ, before taking the muscle out and assessing the

\section{force-length-innervation relation}

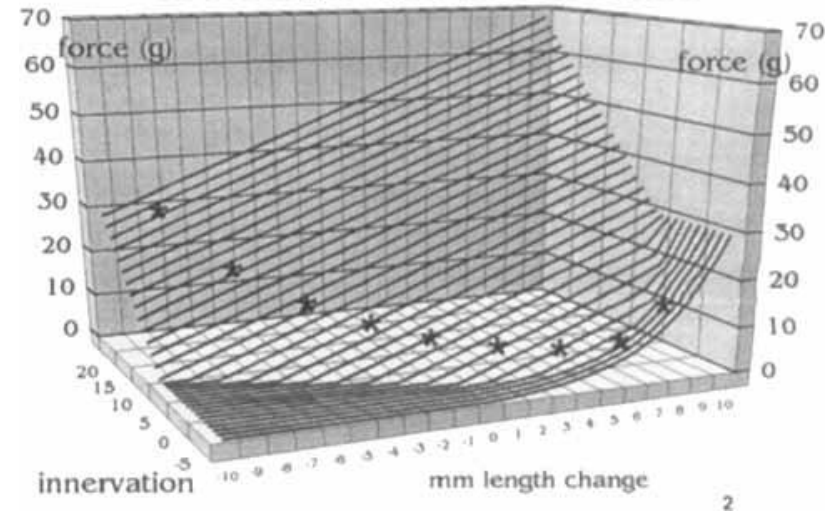


force-length relationship. No other accurate data are available: We found accurate determination of the point at which the muscle length equaled the primary-position length during strabismus surgery to be impossible, because detaching an eye muscle or pulling an eye muscle while still connected to the eye displaces the center of the eye and, hence, mars the measurement.

Collins et al. ( $198 \mathrm{I}$ ) found that the force in a non-contracting human horizontal eye muscle was approximately $23 \mathrm{~g}$ when the eye deviated $45^{\circ}$ out of the field of action of that muscle and that is indeed predicted by the equation.

FORCE-LENGTH RELATION OF CONTRACTING EYE MUSCLES It has been found that the relation between force and length of a contracting eye muscle is linear and, in addition, that the spring constant of a contracting eye muscle remains approximately the same whether the muscle contracts moderately or strongly (Collins et al., 1969; Robinson et al., I969; Simonsz et al., I988; Simonsz, I994). What mechanism is responsible for this linear relation between force and length? How can the relation between force and length of a contracting eye muscle be linear when its component forces, i.e. force generated by the sarcomeres (active component) and force resulting from stretch of the connective tissue in eye muscles (passive component) are both non-linear? For most skeletal muscles, the force generated actively by the sarcomeres, at a given level of innervational stimulation, is low when the muscle is short, is at its highest at a length slightly longer than the average in-vivo length, to decline again when the muscle is stretched further. The reason for maximal-force development to occur at a particular muscle length, is that at this length the intertwining actine and myosine molecules are engaged over a distance that permits the largest possible number of actin-myosin crossbridges to contract unencumbered (Gordon et al., I966). So when a short, contracting muscle is stretched, at first the force generated by the sarcomeres rises proportionately to the length. As the muscle is stretched further the force generated by the sarcomeres decreases. At that point, however, the force resulting from stretch of the connective tissue (the passive component) increases very rapidly, so that the sum of the two forces still rises linearly.

The slope constant of the linear force-length relation of the muscle in the contracting state is the spring constant of the muscle. The force-length relation is different for each level of innervation, but the spring constant of a contracting eye muscle remains approximately the same whether the muscle contracts moderately or strongly (Simonsz et al., 1988; Simonsz, I994) (Fig. 2, series of curves left in diagram).

In patients that underwent first surgery for horizontal strabismus we recorded force and length of horizontal rectus muscles that contracted after intravenous administration of succinylcholine. For these muscles, we found spring constants between $\mathrm{I} .75$ and $2.75 \mathrm{~g} / \mathrm{mm}$ (Simonsz et al., 1988). (For your convenience, the spring constant may be converted to unit gram per degree of eye rotation $\left(\mathrm{g} /{ }^{\circ}\right)$ by dividing by $4.89 ; \mathrm{I} \mathrm{mm}$ on the surface of the average adult eye with a $23.4 \mathrm{I} \mathrm{mm}$ radius equals 4.89 $\mathrm{mm}$.)

The spring constant of a muscle was approximately the same at different levels of contraction (i.e. during diminishing action of succinylcholine). We also found that the spring constants of two muscles of a pair, like the medial and lateral rectus muscle of one eye, were approximately the same.

In a later study, we recorded force and length of isolated, human eye muscles during strabismus surgery in local, eye-drop anaesthesia in 32 adult patients (Simonsz, 1994). From each muscle three recordings were made: (I) while the patient looked with the other eye into the field of action of the recorded muscle, (2) while the patient looked ahead, and (3) when the patient looked out of the field of action of the recorded muscle. Non-contracting eye muscles (state 3) had an approximately exponential relation between force and length. During contraction evoked by letting the patient look ahead or into the field of action of the muscle (states I or 2), the relation between force and length was grossly linear.

In four patients both horizontal rectus muscles were measured. They had not been operated before. The approximate spring constants of these muscles ranged from 2 to $4 \mathrm{~g} / \mathrm{mm}$. The average, $3 \mathrm{~g} / \mathrm{mm}$, seems rather high, considering the fact that the spring constant in passive, horizontal rotation of the eye was found to be $0.99 \mathrm{~g} /{ }^{\circ}$ (Collins et al., I98I) and $0.9 \mathrm{I} g /^{\circ}$ (Simonsz, I986), with a large spread. The spring constant in passive, horizontal rotation of the eye in awake volunteers (muscles attached to the eye) is approximately equal to the sum of the spring constants of the two horizontal rectus muscles and the spring constant of the connective tissue surrounding the eye. $3 \mathrm{~g} / \mathrm{mm}$ would convert to $0.6 \mathrm{~g} /{ }^{\circ}$ in the average adult eye and twice that value, for lateral and medial rectus muscles, respectively, plus the connective tissue component, would add up to well over o.9I or $0.99 \mathrm{~g} /{ }^{\circ}$. Possibly the high spring constants of the three out of four patients we measured were related to the fact that these three had phorias. 
In the original model of Robinson the medial and inferior rectus muscles were assumed to be stiffer than their respective antagonists, because they are thicker and (medial rectus only) shorter. This issue has been discussed above. We found almost equal spring constants for antagonists. This also seems more plausible, because otherwise the total retractile force of the horizontal rectus muscles on the eye would vary with ad- or abduction, with resulting retraction in adduction. As the center of rotation (actually the centroid of rotation) is nasal of the visual $( \pm 0.9-1.6 \mathrm{~mm})$ and of the optic $( \pm 0.3-1 \mathrm{~mm})$ axes (Park and Park. 1933), a slight difference between the two spring constants and the two base forces is nevertheless possible. We found only $14 \%$ difference between the spring constants of the medial and lateral rectus for gaze ahead in the four patients where both muscles were measured: no difference, however, when the measurements made in left and right gaze were also taken into account (Simonsz. I994).

A continuous transition from the linear contractingmuscle relation to the exponential non-contracting-muscle relation is obtained in the model by calculating the force in the muscle according to both the exponential function and to the linear equation and then adopting the larger value (Fig. 2).

The above discussion on muscle spring constant pertains to large, slow and continuous changes in force and length. When the changes in length are small, muscle spring constant is higher: the muscle then behaves like a stiff. lightly damped spring. When the speed of contraction is high or the change in length is large, the muscle cannot generate as much force: then the muscle behaves like a more heavily dampened viscoelastic system (Rack. 1987: Morgan, 1987).

Sarcomeres can generate maximal force (active component) at a muscle length slightly longer than the average in-situ length, this length varying slightly per muscle-fibre type (Heckman et al.. 1992). The muscle length at which maximal force can be developed shifts when speed of contraction is high: In rat gastrocnemius and extensor digitorum longis, Zuurbier et al. (1995) found a longer sarcomere length $(2.69 \mu \mathrm{m})$ for maximal force development on twitch stimulation than the sarcomere length for maximal force development on 100 or $300 \mathrm{~ms}$ of tetanic stimulation $(2.38 \mu \mathrm{m})$. This could, in his opinion, be explained by an increased $\mathrm{Ca}^{2+}$ sensitivity at longer sarcomere length.

In tendons, the relation between force and length is also exponential. In vivo the strain of a tendon does not exceed $\pm 2 \%$ : at $\pm 8 \%$ a tendon tears (Rack, 1987).
Hence, the elasticity of the tendons can be ignored in the model.

DERIVATION OF RECIPROCAL INNERVATION OF ANTAGONISTS FROM DATA MEASURED IN VIVO In the model, the innervation of two muscles of a pair is assumed to be reciprocal (Sherrington, I 896; Sherrington and Hering, 1897). This is a very reasonable assumption. Only during sleep the force of agonist and antagonist are reduced simultaneously (Henn et al., I984). During "scrutinizing" eye retraction occurs, indicative of increase of force in all four rectus muscles (Enright and Hendriks, I 994).

Assuming that the innervation of two muscles of a pair is reciprocal reduces the number of innervation parameters from six to three, one for each muscle pair. What is, however, the relation between the levels of innervation of two muscles of a pair ? Here the finding that contracting eye muscles have linear relations between force and length simplifies matters further, in that the innervation parameter can be represented by the theoretical muscle length at zero force (the intersection of the linear force-length relation with the abscissa).

These two simplifications facilitate direct derivation of the equation describing reciprocal innervation from in vivo measured data: (I) the exponential force-length relation for a non-contracting eye muscle, (2) the spring constant of a contracting eye muscle, (3) the spring constant of the connective tissue surrounding the eye and (4) the tension in a horizontal rectus muscle in gaze ahead.

First the force in a horizontal rectus muscle is calculated when the eye looks $30^{\circ}$ out of the field of action of this muscle. This can be calculated using the exponential function for a non-contracting eye muscle described above; it is assumed that the level of innervation for this position of gaze is zero. To this the force is added caused by deformation of the connective tissue surrounding the eye (see below). The sum of these two forces is the force that the agonist muscle must overcome to hold the eye $30^{\circ}$ into its field of action. As the spring constant of a muscle in the contracting state is also known, the force-length relation and the innervation parameter for a muscle innervated as for $30^{\circ}$ gaze into the field of action of that muscle $\left(\mathbf{I}_{\text {agonist }}\right)$ can be derived.

The force-length relation and the innervation parameter for a contracting horizontal rectus muscle innervated as for primary-position ( $I_{\text {primary-position }}$ ) is derived from the force of the muscle in primary position (approximately $8 \mathrm{~g}$ ) and the spring constant of a muscle in the contracting state. 
At low levels of innervation, the exponential forcelength relation for the non-contracting muscle predominates. A continuous transition from the linear contracting-muscle relation to the exponential non-contractingmuscle relation is obtained in the model by calculating the force in the muscle according to both the exponential function and to the linear equation and then adopting the larger value. The lowest possible level of innervation, zero innervation ( $I_{\text {antagonist }}$ ), can then be described by a tangent to the exponential force-length relation with a slope equal to the known spring constant of the muscle in the contracting state.

Intermediate force-length relations with innervation levels between $\mathrm{I}_{\text {primary-position }}$ and $\mathrm{I}_{\text {antagonist }}$ generated by this model have a profile very much like those measured in vivo during gaze out of the field of action of the muscle (Simonsz, I994).

For reciprocal innervation the equation as suggested by Robinson (1975) is used, based on the findings of Collins et al. (I98I):

$\left(\mathrm{I}_{\text {primary-position }}+\mathrm{W}\right)^{2}=\left(\mathrm{I}_{\text {agonist }}+\mathrm{W}\right) \times\left(\mathrm{I}_{\text {antagonist }}+\mathrm{W}\right)$

From this equation the constant $\mathrm{W}$ is derived, determining reciprocal innervation for all three muscle pairs.

RELATIVE SPRING CONSTANTS OF MUSCLE PAIRS

Robinson (1975), following the general principle that muscle strength is proportional to the cross-sectional area of the muscle, assigned a relative-strength value to each muscle based on the measurements of Volkmann of cross-sectional area (LR: I.00, MR: I.04, SR: 0.68, IR: 0.95 , SO: 0.50, IO: 0.47 ). We found, however, that the spring constants of an agonist and antagonist of a muscle pair are almost similar (Simonsz et al., I988; Simonsz, I994), so in our model the spring constants of agonist and antagonist are equal. What remains uncertain, however, is how the spring constants of the vertical rectus muscles and those of the oblique muscles are related to those of the horizontal rectus muscles.

In our force-length measurements during general anaesthesia, the spring constants of six first-operated vertical rectus muscles during succinylcholine induced-contraction were $1.75 \mathrm{~g} / \mathrm{mm}$, on average, as compared to $2 . \mathrm{I}$ $\mathrm{g} /{ }^{\circ}$ for horizontal rectus muscles. In our series of forcelength recordings from isolated, human eye muscles during strabismus surgery in local, eye-drop anaesthesia, spring constants for first operated vertical rectus muscles were 2 and $4 \mathrm{~g} / \mathrm{mm}$. Only two muscles were measured, however.

For oblique muscles, the situation is more uncertain.
In oblique muscles we frequently found nonlinear forcelength relations, both during succinylcholine-induced contraction and during recordings during strabismus surgery in local, eye-drop anaesthesia. The spring constants for oblique muscles found in recordings during strabismus surgery in local, eye-drop anaesthesia were between 2 and $4 \mathrm{~g} / \mathrm{mm}$, like those of horizontal rectus muscles. If we would assume such a high spring constant for the oblique muscles, however, we run into a problem: The spring constant in passive, torsional rotation of the eye in awake volunteers (eye with all muscles attached) is only $0.625 \mathrm{~g} . \mathrm{cm} /{ }^{\circ}$, on average (Simonsz et al., 1984), or $0.534 \mathrm{~g} /{ }^{\circ}$ when the force is applied at the equator of the eye, assuming a radius of II.7I mm. This spring constant is reached in the model when the spring constants of the oblique muscles are set at around I $\mathrm{g} / \mathrm{mm}$, much lower than those measured in vivo. It is possible that the muscle fibre-type composition and the recruitment order is different in oblique versus rectus muscles. Shall and Goldberg (I995) recently stimulated 4I single abducens nucleus motoneurons in the cat evoking electromyographic and contractile responses in the ipsilateral lateral rectus muscle. Separate, bipolar, fine wire EMG recording electrodes in the global and orbital muscle layers showed that 22 muscle units were confined to the global layer, 8 to the orbital layer, and I I units were contained in both ("bilayer") muscle layers. Bilayer units demonstrated significantly greater twitch and maximum tetanic forces as well as faster fusion frequencies than either global or orbital units. They were predominantly fast fatigable. They had the lowest average slope of the linear relationship between motoneuron stimulation frequency and isometric tetanic force. A relative preponderance of such units in oblique muscles would explain the relatively high spring constants of oblique muscles found in vivo; the base force in an oblique muscle would then be low.

The model handles forced-duction tests and various kinds of surgery best with the relative spring constant of the vertical rectus muscles set at $80 \%$ and that of the oblique muscles at $40 \%$ but, admittedly, the latter has not been derived from in vivo measurements.

SPRING CONSTANT OF THE CONNECTIVE TISSUE SURROUNDING THE EYE (PASSIVE ROTATION OF THE EYE WITHOUT MUSCLES) The force in deformation of the connective tissue surrounding the eye is found by multiplying the angle of eccentric gaze by the spring constant in such rotation. For instance, if the eye is $20^{\circ}$ out of the primary position, in any direction, and the spring constant is $0.3 \mathrm{~g} /{ }^{\circ}$, the force is $6 \mathrm{~g}$ towards the 
primary position, which can then be split into horizontal and vertical components. The same is done for torsional eye rotation.

The force in passive rotation of the eye without muscles is caused by deformation of retrobulbar fat, connective-tissue septa and the optic nerve. It cannot be measured in vivo as accurately as the force of eye muscles because passive rotation of the eye. applied with a forceps to a point of the sclera for instance. will confer displacement of the center of the eye that mars the measurement.

A second problem is that it is unknown whether the spring constant of the connective tissue is the same in the torsional direction as compared to the horizontal or vertical directions. Direct measurement of the spring constant of the connective tissue in torsion is impossible in vivo: One would have to sever all muscles from the eye and then ex-or intort the eye.

In early measurements (Robinson et al., I969) a value of $0.48 \mathrm{~g} /{ }^{\circ}$ was found for spring constant of the connective tissue in horizontal rotation of the eye, but this value is definitely too high. as the spring constant in horizontal, passive rotation of the eye with muscles attached, is 0.9 to $1.0 \mathrm{~g} /{ }^{\circ}$ (Collins et al., $198 \mathrm{I}$ ), and the spring constant in passive, torsional rotation of the eye with muscle attached, is $0.534 \mathrm{~g}^{\circ}$, on average (Simonsz et al., I984). If we, being short of further data, assume that the horizontal, vertical and torsional values are equal, trial runs with the computerized model yield $0.30 \mathrm{~g} /{ }^{\circ}$ as a reasonable approximation for all three. The spring constants in passive horizontal, vertical and torsional rotation of the eye, with muscles attached. are then $1.10 \mathrm{~g} /{ }^{\circ}, 0.90 \mathrm{~g} /{ }^{\circ}$ and $0.54 \mathrm{~g} /{ }^{\circ}$, respectively, the first and third of these values being close to the values measured in vivo.

A simple linear relation for the spring constant of the connective tissue seems adequate. Robinson (1975) added a third-power function that increased the spring constant at large gaze eccentricities, but this contrasts with the fact that the spring constant in passive, horizontal (Collins et al., 198I) and torsional (Simonsz, 1984) rotation of the eye remains approximately the same over a large range.

With $2 \mathrm{~g} / \mathrm{mm}$ as spring constant for a horizontal rectus muscle and $0.30 \mathrm{~g} /{ }^{\circ}$ as spring constant of the connective tissue surrounding the eye, the model predicts a response-dose ratio for surgery on horizontal rectus muscles of $1.72 \%$ mm (degrees of strabismus-angle change per millimeter of muscle shortening or lengthening). which is approximately the response-dose ratio found clinically (Simonsz and van Dijk, I988).
PATH OF THE EYE MUSCLES IN EYE MOVEMENTS OUT OF THE PLANE OF THE MUSClE In Robinson's model, the muscle, represented by a string, followed a circular path on the eye from the insertion to the point of tangency, and a straight path from the point of tangency to the origin of the muscle. If the eye muscles would follow the shortest possible path over the eye under all circumstances, the circular path of the muscle over the globe would always be an are of a great circle on the globe. The sideslip of the muscle over the eye would become very large in eye movements out of the plane of action of the muscle, causing twist of the tendon of the muscle at the insertion and a bridle effect (horizontal rectus muscles becoming elevators in upgaze, for instance).

Krewson's calculations (1950) were based on this assumption, and in his model, in eye movements out of the plane of the muscle, a large sideslip of the muscle over the eye, a large twist of the muscle tendon at the insertion and a large bridle effect occurred.

A first reservation about this assumption had already been formulated by von Helmholtz: if the band-like tendon twists at the insertion, only part of the tendon would be taut (von Helmholtz, I910; Boeder, 1961). For instance, in adduction only the temporal part of the superior rectus tendon is taut and, hence, the effective insertion shifts temporally. Consequently, the direction of pull of the muscle changes less than the twist angle of the tendon at the insertion. Haase and Kusel (1977) modified their version of the computerized model in that the effective insertion point of the muscle shifted in eye movements out of the plane of the muscle.

To elucidate the path of the eye muscles in eye movements out of the plane of the muscle, we previously made CT-scans in six volunteers, in a plane perpendicular to the orbital axis at the level of the posterior pole of the eye (Simonsz et al., I985), as had been suggested to us by J.M. Miller. Surprisingly, in that plane no sideways displacement of the rectus muscles occurred, in eye movements out of the plane of the muscle, i.e. horizontal rectus muscles in up- or downgaze, and vertical rectus muscles in left and right gaze. We then made CTscans in a horizontal plane and found that the rectus muscles followed a path curved outward (i.e. towards the orbital wall) when the eye was in primary position. The curvature increased on relaxation and decreased on contraction. It was less in the medial rectus than in the lateral rectus, possibly because the oblique muscles pull the eye medially.

We hypothesized that the curvature of the rectus muscles is caused by build up of pressure behind the eye, 
caused by the rectus muscles themselves as they pull the eye against the fat pad behind the eye and primarily contained within the muscle cone (Simonsz et al., I985). With $8 \mathrm{~g}$ pull per rectus muscle in gaze ahead and an effective cross-sectional area of the eye and adnexa of $7.5 \mathrm{~cm}^{2}$ (deduced from post mortem assessment of the force/retrobulbar-pressure relationship, by placing weights on the eye and measuring retrobulbar-pressure rise), we estimated the retrobulbar pressure to be about $3 \mathrm{~mm} \mathrm{Hg}$, rising in eccentric gaze and during eye movements. Later, slightly higher values were found in vivo by Otto (I991a) in normal cynomolgus and rhesus monkeys. Otto (I99 Ib) found pressures up to $28 \mathrm{~mm} \mathrm{Hg}$ in patients with Graves' disease, however.

In anatomical sections through the orbit by Koornneef (1977a, Chapter 4, Figs. 8-10; Chapter 5, Figs. 8-I I), it can be seen that connective tissue septa bulge out between adjacent rectus muscles, something we would interpret as an indication of the build-up of pressure and the partial containment of that pressure within the muscle cone. Sections by Demer et al. (1995, Fig. 7) show the same thing: A crosscut connective-tissue membrane encircles the lateral rectus muscle on the global side of the muscle, and then follows a path curved outward, towards the superior rectus and towards the inferior rectus muscles. Both Koornneef and Demer do not explicitly label this as the intermuscular membrane, however.

It seems likely that the eye is suspended in the orbit primarily by a push-pull mechanism consisting of the rectus muscles pulling the eye together against the fat pad behind the eye. The former concept of the eye being suspended in the orbit by means of the check ligaments

Fig. 3. It seems likely that the eye is suspended in the orbit primarily by a push-pull mechanism consisting of the rectus muscles pulling the eye together against the fat pad behind the eye. The former concept of the eye being suspended in the orbit by means of the check ligaments is naive, because the eye can freely rotate $90^{\circ}$ horizontally and $80^{\circ}$ vertically. The rectus muscles together pull the eye backwards in the orbit, which inevitably results in retrobulbar pressure. This retrobulbar pressure is contained by connective tissue septa, part of which constitute the intermuscular membrane. The intermuscular membrane is depicted in this figure as a translucent membrane. It follows that sideways displacement of the rectus muscles in eye movements out of the plane of the muscle is restricted not only by the pulleys and sleeves described by Demer at al. (I995), that connect the rectus muscles to the orbital wall, but also by the tension in the intermuscular membrane resulting from the containment of the retrobulbar pressure in the muscle cone. is naive, because the eye can freely rotate $90^{\circ}$ horizontally and $80^{\circ}$ vertically.

It follows that sideways displacement of the rectus muscles in eye movements out of the plane of the muscle is restricted not only by the pulleys and sleeves described by Demer at al. (I995), that connect the rectus muscles to the orbital wall, but also by the tension in the intermuscular membrane resulting from the containment of the retrobulbar pressure in the muscle cone (Fig. 3).

To envisage this concept, one can think of the rectus muscles as bands encircling a balloon (the intermuscular membrane): The tension in the wall of the balloon will prevent sideways displacement. When the anterior delimitation of the balloon, i.e. the eye, turns left, right, up or down, the entire balloon deforms. The fact that the muscles are not lying directly on the eye at the level of the equator of the eye (Demer et al., 1995), is also explained by the build up of pressure in the muscle cone.

The basic premise of the model that the center of the eye is fixed in the orbit, whereas in reality the eye rolls on the fat pad behind the eye, is a shortcoming of the model that is not easily remedied. With computer calculating power going up steadily, it may become possible in the future to model the fat pad as a viscoelastic compartment with drop-off of pressure across the intermuscular membrane and other membranes between eye, eye muscles and orbital wall, under static conditions and during eye movements.

DIRECTION OF PULL OF THE EYE MUSClES David Robinson assumed that the muscle followed a straight path from its origin to the point of tangency of the muscle to the eye, and imparted its force to the eye at that point of tangency (Fig. 4, arrow I). Apart from the fact that the point of tangency lies more anteriorly than predicted by this assumption (Demer et al., I995), it is doubtful whether any muscle force is imparted to the eye at the point of tangency at all. The friction between the

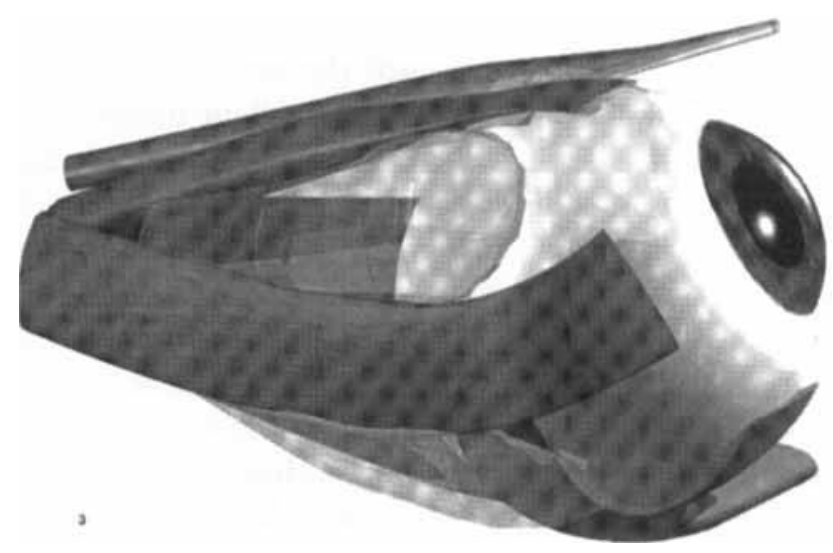




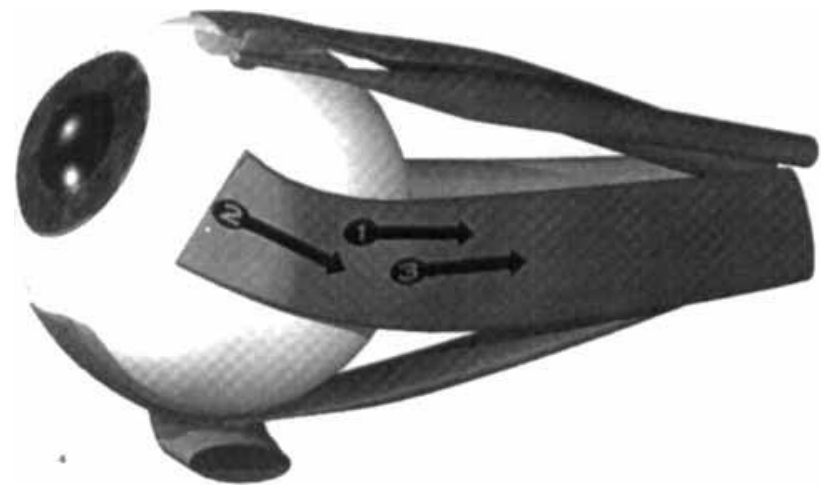

tendon and the eyeball is extremely low, as the muscle and tendon are embedded in connective-tissue sheets that slide smoothly over each other. It seems more likely that most of the force is imparted to the eye at the insertion of the muscle. The question then remains what generates the force that prevents sideways displacement of the muscles in eye movements out of the plane of the muscle. As said above, sideways displacement is prevented by connective-tissue sheets that fan out towards the eye and towards the orbital wall.

If the connective-tissue sheets fan out mainly to the eye, the effective direction of pull of the muscle will remain constant relative to the orbit in eye movements out of the plane of the muscle (Fig. 4, arrow 3). If, however, the connective-tissue sheets fan out mainly to the orbital wall, the effective direction of pull of the muscle will rotate with the eye, in eye movements out of the plane of the muscle (Fig. 4, arrow 2). In as much as they fan out towards each other, via the muscle cone, forces are annihilated.

Amazingly, the predictions of the computerized model were, in a simulation, very similar whether we let the muscles pull in a direction constant relative to the orbit or rotating with the eye. A larger difference existed between these two and Robinson's original, point of tangency model, even though in that version the permitted twist of the muscle at the insertion had been reduced to zero.

In this simulation we tested the predictions of the model of oblique muscle palsy and oblique muscle surgery against a series of 200 patients that underwent oblique muscle surgery (Kolling, I986; all angles of strabismus measured in nine positions of gaze). The three versions of the model did not differ significantly in their predictions of the angles of strabismus in a trochlear palsy. This had also been found by Clement (I985).

For instance, excyclotropia was not influenced to any large extent by ad- or abduction, as had been found by Kolling (classically, the oblique muscles are considered
Fig. 4. In Robinson's original computerized model, some sideslip of the muscle over the eye was permitted in eye movements out of the plane of the muscle. In addition, the muscle pulled at the calculated point of tangency (arrow I). The path of the muscle was straight from the origin to the point of tangency and then followed a lesser circle on the globe (the shortest possible path over a globe is always part of a great circle). However, the muscles do not displace at the level of the posterior pole (Simonsz et al., I 985, Miller and Robins, I987; Miller, I989; Demer et al., I995), but are held in place by connective tissue septa, like muscle pulleys (Miller, 1989) connected to the orbital wall (Demer et al., I 995) and the intermuscular membrane (Fig. 3). If the connective tissue septa that hold the muscle belly in place mainly fan out towards the orbital wall, the effective direction of pull of the muscle will rotate with the eye in eye movements out of the plane of the muscle (arrow 2). If, on the other hand, they mainly fan out towards the eye and towards each other via the intermuscular membrane, the effective direction of pull of the muscle will remain constant in the orbital frame (arrow 3). We agree with Miller (1989) that the truth will probably be between the latter two, so in the model the average of these two directions of pull is taken.

to be mainly torters when the eye is in abduction, and elevators and depressors when the eye is in adduction).

Secondly, Kolling found that surgery on the oblique muscles not only changed the vertical divergence in adduction but also the vertical divergence in abduction considerably (20-30\% of the change in $25^{\circ}$ adduction). This also was predicted by the model (it is the reason for a contralateral superior oblique palsy to become 'manifest' after ipsilateral oblique-muscle surgery). As said above, the predictions of the computerized model corresponded well to the actual results and were almost similar whether we let the model eye muscles pull in a direction constant relative to the orbit or in a direction that rotated with the eye. A larger difference only existed between these two and Robinson's original, point-oftangency model,

We agree with Miller (1988) that the truth will probably be somewhere between the latter two. To approach that reality as much as possible, we have the model calculate the direction of pull rotating with the eye and the direction of pull remaining constant in the orbital frame, and then take the average direction.

\section{Discussion}

CURRENT MODE OF OPERATION The computerized strabismus model that has resulted from the modifica- 
tions as discussed above consists of two programs. The first program derives the levels of innervation of the six eye muscles from a given eye position, whereas the second program derives the eye position from the six levels of innervation. This procedure is carried out either for nine positions of gaze $\left(25^{\circ}\right.$ up- \& $25^{\circ}$ left-gaze, $25^{\circ}$ upgaze etc.), for five positions of gaze (up, left, ahead, right and down), for three positions of gaze (left, ahead and right or up, ahead and down) or for one position of gaze (ahead). Both programs use the same set of parameters describing the anatomy of an average adult eye (eye size, insertions and origins) and the mechanical characteristics of the eye muscles. In the program that derives eye position from innervation, however, these parameters can be changed so that, for instance, surgery can be modelled. A palsy can be modelled by making the innervation for a particular muscle zero.

The first program starts by asking the user whether he wishes to alter the default mechanical properties of the model eye muscles and those of the connective tissue surrounding the eye. The default values were derived from a large study of force-length recordings made during strabismus surgery under local, eye-drop anaesthesia, as described above. From these values many other parameters, like the parameters describing the reciprocal levels of innervation of antagonists, were derived. The use of free parameters is thereby avoided. The program then asks the user to enter axial length of the eyes of the patient or, alternatively, age, sex and refraction, so that axial length can be derived. From the axial length a scaling factor is derived that is multiplied throughout the program with all values that are subject to change with the size of the eye.

The right or the left eye is designated as the strabismic eye and the user enters horizontal, vertical and torsional angles of strabismus of the patient for, as he elects, nine, five, three or one positions of gaze. The program assumes that the patient fixated the $25^{\circ} / 25^{\circ}$ cardinal positions during the actual measurements of the angles of strabismus with the other eye. The angles of strabismus are converted by the program to absolute eye positions. In case the angles of strabismus have been measured during fixation at near, absolute eye position is found by adding $5^{\circ}$ of adduction for each eye. The program calls the main subroutine to calculate the exact positions of the origins and the insertions of the eye muscles. The program calls a subroutine that calculates the levels of innervation of the six eye muscles needed to get the strabismic eye in the given nine, five, three or one positions of gaze. The subroutine has an approximation loop that starts with an initial guess of the six levels of innervation (three pairs of reciprocal innervation) and calculates, with a given eye position, the sum of all forces of the muscles and of the connective tissue surrounding the eye. Guided by the size and the direction of the remaining force it guesses the levels of innervation again and again until the sum of forces is almost zero.

The levels of innervation are stored in a file on the harddisk, together with other information concerning the mechanical properties of the muscles, the size of the eye, the strabismic eye, fixation at near or at distance and the number of positions of gaze. The name of the patient is entered as filename.

The second program first prompts the user for this filename and collects the file. Then the user can enter all kinds of strabismus surgery: recession, resection, transposition (moving the insertion sideways) or Faden surgery (suturing the belly of the muscle to the eye I2-I4 $\mathrm{mm}$ posterior from the insertion).

Forced duction can be modelled by adding an external force. A palsy is modelled by decreasing the innervation of a muscle. Overaction is modelled by increasing the innervation of a muscle ('overaction' erroneously implies an infranuclear disorder, whereas such motility disorders actually have a multifactorial cause, Liesch and Simonsz, I993). Finally, fibrosis of a muscle can be modelled by changing the exponential force-length relation for the non-contracting eye muscle: The muscle can be made shorter or stiffer or both. To model a palsy or fibrosis of an eye muscle, the user starts by entering $0^{\circ}$ angles of strabismus in the first program and then models a palsy or fibrosis on this normal eye in the second program.

The second program calls a subroutine that calculates the new positions of the origins and the insertions after surgery. Then it calls the main subroutine that calculates the position of the strabismic eye for nine, five, three or one positions of gaze. The subroutine has an approximation loop that starts with an initial guess of the eye position. It calculates the sum of all muscle and connectivetissue forces, with a given level of innervation for all three muscle pairs. Guided by the size and the direction of the remaining force it guesses the eye position again and again until the sum of forces is almost zero. From absolute eye positions the angles of strabismus are derived and presented graphically, in a way similar to a Hess chart. When the other eye is also being operated, first the levels of innervation of that eye are calculated assuming $o^{\circ}$ angles of strabismus for that eye.

Concluding remarks In this review we have not described the actual writing and optimizing of the pro- 
grams, because only a handful of people would be interested in that and, instead. the source code of the programs has been richly supplied with comment lines that explain how the program works. The algorithms have been speeded up to the extent that a calculation for nine positions of gaze now takes ten seconds on a handheld HP 20oLX Palmtop. Considering the fact that on a XT, which is about as fast as a HP 200 LX Palmtop, the program originally took 5 minutes for nine positions of gaze, a considerable gain in speed has been reached.

The fact that the program runs well on a handheld PC is relevant: In our experience it is not really possible, when deciding what to operate the next day, to interrupt a meeting with the patient and the orthoptists to find a desktop PC to do some calculating work. whereas the use of a handheld PC during such meeting is well accepted by patients, especially when their case is complex.

The predictions of the model compared well with clinical results in simulations of horizontal muscle surgery, of oblique muscle surgery, of abducens, oculomotor or trochlear palsies, and of various forced duction tests. Consequently, all complex strabismus surgery in our clinic is now guided by the predictions of the computerized strabismus model.

The user should be well aware of the model's limitations, however. For instance, the model only describes an average eye of an adult or child and does not take anatomical variations into account. These variations go far beyond variations in the insertions and origins of oblique muscles. Simpson (quoted by Crawford, 1994) found about $7^{\circ}$ of variation between the muscle planes of the horizontal rectus muscles in four monkeys. The brainstem easily deals with these variations, employing binocular vision (Viirre et al., 1987, 1988; Liesch and Simonsz, 1993), with (Crawford, 1994) or without (Robinson, 1992) intrinsic compliance of the brainstem with Listing's law. The computerized model here has a severe limitation in that it only deals with the average eye, at the level of the eye muscles. It considers all forms of strabismus as given, supranuclear disorders. In work to come we will present results in 60 patients operated with the help of the computerized model and show that patients with an aberrant eye motility caused by an orbital fracture, for instance, are therefore particularly difficult to model; the mechanical properties of the scar tissue in their individual case cannot be known in detail preoperatively.

The two programs are distributed as shareware and can be obtained directly from the first author on request. The source code of the programs is also available, for registered users. The authors distribute the computerized model in the public domain with the urgent wish that those who improve the model further will also keep the model in the public domain, to keep research communication channels open.

Acknowledgments We thank David A. Robinson, Gerhard Asmussen, Gerold H. Kolling, Joel M. Miller, Richard A. Clement. Guntram Kommerell and Herbert Kaufmann for many helpful discussions. This work was supported by a fellowship of the Royal Netherlands Academy of Arts and Sciences to the first author.

\section{References \\ Asmussen G. Morphologische, physiologische und \\ pharmakologische Eigenschaften der äusseren Augenmuskeln und ihre Veränderungen nach Denervation, Dissertation, Leipzig. 1978. Boylan C. Clement RA. Excursion tests of ocular motility. Ophthal Physiol Opt 1987: 7:31-35. \\ Bredner-Hirr A. Einfluß der Obliquus-Inferior-Ricklagerung auf den Horizontalwinkel. Abstract. Meeting of the Berutsverband der Orthoptistimnen Deutschlands. Region Baden-Württemberg. Esstingen. May}

1976.

Clement RA. Computer simulation of extraocular muscle co-operation: an evaluation. Ophthal Physiol Opt 1982: 2:107-117.

Clement RA. A comparison of different models of extraocular muscle cooperation. Ophthal Physiol Opt 1985:5:165-170.

Clement RA. Description of the length-tension curves of the extraocular muscles. Vision Res 1987 ;

27:491-492.

Clement RA, Howrie A. Computer modelling of the muscular factors involved in the aetiology of $\mathrm{A}$ and $\mathrm{V}$ syndromes. Brit Orthopt J 1985 ; 42:65-68.

Collins CC, Scott AB, O'Meara DM. Elements of the peripheral motor apparatus. Am J Optom I969; 46:510-515. Collins CC, Carlson MR, Scott AB. Jampolsky A. Extraocular muscle forces of normal human subjects. Invest Ophthalmol Vis Sci $198 \mathrm{I}$; 20:652-664.

Crawford JD. The oculomotor neural. integrator uses a behavior-related coordinate system. J Neurosci 1994; I 4:69 I I -23.

Demer JL, Miller JM. Poukens V, 
Vinters HV, Glasgow BJ. Evidence for fibromuscular pulleys of the recti extraocular muscles. Invest Ophthalmol Vis Sci I 995 ; 36: I I 2536.

Diamond GR, Parks MM. The effect of superior oblique weakening procedures on primary position horizontal alignment. J Pediat Ophthalmol \& Strabismus I98 I; I 8:35-38.

Donders FC, Doijer D. De ligging van het draaipunt van het oog. Wetenschappelijk Bijblad Jaarverslag Ooglijdersgasthuis 3:2 10-228, Utrecht, I 862.

Enright JT, Hendriks A. To stare or to scrutinize: "Grasping" the eye for better vision. Vision Res I994; 34:2039-2042. Fick A. Die Bewegungen des menschlichen Auges. Zeitschr f Rat Med 1854; 4: IOI-I 28. Fink H. Surgery of the vertical muscles of the eye. 2nd edit, $\mathrm{CC}$ Thomas, Springfield, 1962. France TD, Burbank DP. Clinical applications of a computer-assisted eye model. Trans Am Acad Ophthalmol Otolaryngol 1979 ; 86: 1407.

Fung YCB. Elasticity of soft tissues in simple elongation. Am J Physiol I $967 ; 2$ I 3: I 532-I 544.

Gordon AM, Huxley AF, Julian FJ. The variation in isometric tension with sarcomere length in vertebrate muscle fibres. J Physiol I966;

I 84:170-192.

Gïnther S, Kusel R, Rassow B Modellmäßige Beschreibung der Augenmuskelwirkung unter Berücksichtigung des Ligamentum Lockwood. Fortschr Ophthalmol I 986; 83:514-7.

Günther S. Die modellmäßige Beschreibung der Augenmuskelwirkung. Diplomarbeit, Fachbereich Physik der Universität Hamburg, 1986.

Haase W. Augenmuskelwirkungen: theoretische Voraussage und klinische Beobachtung. Berichte
Dtsch Ophthalmol Ges I977; 45:459464.

Haase W, Kusel R. Rechnerische und klinische Ergebnisse von

Schieloperationen. In:

Augenbewegungsstörungen, Symp

Dtsch Ophthalmol Ges, Freiburg,

I 977. JF Bergmann Verlag München, I 978, p9 I -95 .

Heckman CJ, Weytjens JLF, Loeb

GE. Effect of velocity and mechani-

cal history on the forces of motor units in the cat medial gastrocnemius muscle. J Neurophysiol I 992;

68: I 503-I 5 .

von Helmholtz $\mathrm{H}$. Handbuch der

Physiologischen Optik, Vol 3. 3rd ed, Leopold Voss, Hamburg \& Leipzig,

I9IO.

Henn V, Baloh RW, Hepp K. The sleep-wake transition in the oculomotor system. Exp Brain Res 1984; 54: I66-76.

Kault DA, Stark DJ, Stark KP.

Further investigation of a strabismus model. Australian and New Zealand J Ophthalmol I987; I 5:43-55.

Kault DA, Stark DJ, Stark KP. An automated system of strabismus management. Invest Ophthalmol 1 989; 30:276-287.

Kolling GH. Diagnostik und operative Korrektur von Vertikal- und Zyklodeviationen bei Störungen schräger Augenmuskeln. Habilitationsschrift, Gießen, 1986. Koornneef L. Spatial aspects of orbital musculo-fibrous tissue in man. Thesis. Swets \& Zeitlinger, Amsterdam, I977a.

Koornneef L. New insights in the human orbital connective tissue. Arch Ophthalmol I 977b; 95:I269-73. Krewson WE. The action of the extraocular muscles. Trans Am Ophthalmol Soc 1950; 48:443. Kusel R, Haase W. Versuch einer mathematischen Darstellung der Augenmuskelwirkung. Ber Dtsch Ophthalmol Ges $1977 ; 45: 453-458$. Lang Joh, Horn T, von den Eichen U. Über die äusseren Augenmuskeln und ihre Ansatzzonen. Gegenbaurs
Morphol Jahrb, I 980; 1 26:8 1 7-840. Larsen JS. The sagittal growth of the eye. IV. Ultrasonic measurement of the axial length of the eye from birth to puberty. Acta Ophthalmol Kbh I97 I; 49:873-886.

-Liesch A, Simonsz HJ. Up- and downshoot in adduction after monocular patching in normal volunteers.

Strabismus 1993; 1:25-36.

Merkel F, Orr AW. Das Auge des

Neugeborenen an einem

schematischen Durchschnitt erläutert.

Anat Hefte I 892; I:273-296.

Miller JM. A model of the mechanics of binocular alignment. Comput Biomed Res 1984; 17:436-470. Miller JM, Robins D. Extraocular muscle sideslip and orbital geometry in monkeys. Vision Res 1987 ; 27:38I-392.

- Miller JM. Functional anatomy of normal human rectus muscles. Vision Res 1989; 29:223-240.

Morgan DL. The length-velocitytension space, and its application to sarcomere non-uniformities. In:

Biomechanics and neural control of movement, Engineering Foundation Conference, Henniker, July I 987. Otto AJ. Volume discrepancies in the orbit and the effect on the intraorbital pressure. In: Effects of volume, force and pressure alterations in the orbit, Chapter V. PhD thesis, University of Amsterdam, r99Ia.

Otto AJ. Compression and decompression of orbital tissues, following intraorbital volume increase in Graves' ophthalmopathy. In: Effects of volume, force and pressure alterations in the orbit, Chapter VIII. PhD thesis, University of Amsterdam, I99 Ib.

Park RS, Park GE. The center of rotation in the horizontal plane. Am J Physiol I933; 104:545-552.

Rack PMH. Physiological properties of mammalian skeletal muscles. In: Biomechanics and neural control of movement, Engineering Foundation Conference, Henniker, July I987. Robinson DA, O'Meara DM, Scott 
$A B$, Collins CC. Mechanical components of human eye movements. $J$ Appl Physiol 1969: 26:548-553. Robinson DA. A quantitative analysis of extraocular muscle cooperation and squint. Invest Ophthalmol Vis Sci 1975: 14:801-825.

Robinson DA. Implications of neural networks for how we think about brain functions. Behav Brain Sci $1992 ; 15: 644-55$.

Shall MS, Goldberg SJ. Lateral rectus EMG and contractile responses elicited by cat abducens motoneurons. Muscle Nerve 1995 : I 8:948-55.

Sherrington CS. On reciprocal innervation of antagonistic muscles, third note. Proc Roy Soc 1896-1897;

60:414-417.

Sherrington CS. Hering EH. Antagonistic muscles and reciprocal innervation, fourth note. Proc Roy Soc $1897^{-}$ 1898:62:183-187.

Simonsz HJ. Investigations of ocular counterrolling and Bielschowsky head-tilt test. stiffness in passive ocular rolling and displacement of recti eye muscles, PhD thesis, Lniversity of Amsterdam. 1984.

Simonsz HJ, Crone RA, de Waal BJ. Schooneman M, Lorentz de Haas HAL. Measurement of the mechanical stiffness in cyclotorsion of the human eye. Vision Res 1984; 24:96I-
968.

Simonsz HJ, Härting F, de Waal BJ. Verbeeten BWJM. Sideways displacement and curved path of recti eye muscles. Arch Ophthalmol 1985: 103:124-128.

Simonsz HJ, Kolling GH, Kaufmann $H$, van Dijk B. Intraoperative force and length curves of human eye muscles and stiffness in passive horizontal eye movement in awake volunteers. Arch Ophthalmol I986; I $4: 1495^{-1} 500$.

Simonsz HJ, van Dijk B. Analysis of the dosage controversy in recessresect and Faden surgery with the Robinson computer model of eye movements. Doc Ophthalmol 1988; 67:237-252.

Simonsz HJ. Kolling GH, Kaufmann H. van Dijk B. Length-tension curves of human eye muscles during succinylcholine-induced contraction. Invest Ophthalmol 1988; 29: I 320I $33 \mathrm{I}$.

Simonsz HJ. The mechanics of squint surgery: length-tension measurements of human eye muscles, their implementation in a computerized model, and analysis of squint surgery with the model. Habilitationsschrift, University of GieBen, I990; Acta Strabologica. 1990, ed: JB Weiss, C.E.R.E.S.. Paris.
Simonsz HJ, den Tonkelaar l. I9th Century mechanical models of eye movements, Donders' law, Listing's law and Helmholtz' direction circles. Doc Ophthalmol I 990; 74:95- I I 2. Stager DR, Parks MM. Inferior oblique weakening procedures: Effect on primary position horizontal alignment. Arch Ophthalmol 1973; 90: I 5-I 6 .

Tatsugami H, Yamamoto M, Bun J. The sagittal growth of the eye in children. Folia Ophthalmol Japonica I 980; 31:574-578.

Viirre E, Cadera W, Vilis T. The pattern of changes produced in the saccadic system and vestibulo-ocular reflex by visually patching one eye. $\mathbf{J}$ of Neurophys 1987; 57:92-103.

Viirre E, Cadera W, Vilis T. Monocular adaptation of the saccadic system and vestibulo-ocular reflex. Invest Ophthalmol I 988; 29:I 339-47.

Volkmann A.W. Ueber die Mechanika der Augenmuskeln. Ber Verh Sachs Wsch 1869; 21:28-69. Weiss L. Beitrag zur Anatomie der Orbita. Tübingen, I 890.

Zuurbier CJ, Heslinga JW, Lee-de Groot MBE, van der Laarse WJ. Mean sarcomere length-force relationship of rat muscle fibre bundles. J Biomechanics I 995; 28:83-87. 